\title{
Kinetic Studies on The Selective Oxidation of Benzyl Alcohol and Substituted Benzyl Alcohols in Organic Medium under Phase Transfer Catalysis
}

\author{
K. Bijudas ${ }^{1 *}$, P. Bashpa ${ }^{1}$, T. D. Radhakrishnan Nair ${ }^{2}$ \\ ${ }^{1}$ Department of Chemistry, N. S. S. College, Manjeri, Malappuram, Kerala - 676122, India \\ 2 Department of Chemistry, University of Calicut, Kerala - 673635, India
}

Received: 16th March 2014; Revised: 18th May 2014; Accepted: 18th May 2014

\begin{abstract}
Kinetic studies on the oxidation of benzyl alcohol and substituted benzyl alcohols in benzene as the reaction medium have been studied by using potassium dichromate under phase transfer catalysis (PTC). The phase transfer catalysts (PT catalysts) used were tetrabutylammonium bromide (TBAB) and tetrabutylphosphonium bromide (TBPB). Benzyl alcohols were selectively oxidised to corresponding benzaldehydes in good yield (above $90 \%$ ). The order of reactivity among the studied benzyl alcohols is $\mathrm{p}-\mathrm{OCH}_{3}>\mathrm{p}-\mathrm{CH}_{3}>-\mathrm{H}>\mathrm{p}-\mathrm{Cl}$. Plots of log $\mathrm{k}_{2}$ versus Hammett's substituent constant $(\sigma)$ has been found to be curve in shape and this suggests that there should be a continuous change in transition state with changes in substituent present in the substrate from electron donating to electron withdrawing. A suitable mechanism has been suggested in which the rate determining step involves both C-H bond cleavage and C-O bond formations in concerted manner. (C) 2014 BCREC UNDIP. All rights reserved
\end{abstract}

Keywords: Benzyl alcohols; Kinetics; Phase transfer catalysis; Phase transferred monochromate; Selective oxidation

How to Cite: Bijudas, K., Bashpa, P., Nair, T.D.R. (2014). Kinetic studies on the selective oxidation of benzyl alcohol and substituted benzyl alcohols in organic medium under phase transfer catalysis. Bulletin of Chemical Reaction Engineering \& Catalysis, 9 (2): 142-147. (doi:10.9767/bcrec.9.2.6476.142-147)

Permalink/DOI: http://dx.doi.org/10.9767/bcrec.9.2.6476.142-147

\section{Introduction}

Various forms of chromate are used in the kinetic studies of the oxidation of benzyl alcohols in aqueous and in other polar solvents [1$2]$. But there are very little information regarding the kinetics of corresponding reactions in non polar solvents [3-5]. This is because; most of the organic substrates are soluble in non polar solvents while oxidants are soluble only in polar solvents. So rapid stirring, high tempera-

\footnotetext{
* Corresponding Author.

E-mail: bijudask@gmail.com (K. Bijudas)
}

Tel: +91 9447170209, Fax: +91 4832766202 ture and use of toxic dipolar aprotic solvents are the ways to carry out and to speed up such a reaction. All these methods have lot of disadvantages like low yield, high activation energy requirement, expensive reactants, low selectivity, use of toxic and expensive solvents, higher amount of byproducts etc. Phase transfer catalysis (PTC) can overcome these limitations and is highly significant in the era of green chemistry. Phase transfer catalysts (PT catalysts) can carry the active oxidant anions from the polar solvent to non polar solvent as an ion pair and thus by effecting the reaction in organic medium with ease. 
Chromate ions have been found to be very effective in the oxidation of benzyl alcohols to benzaldehyde under organic medium in synthetic aspects using PT catalysts [6-7]. Even though there are lot of reports on the kinetics of oxidation of various organic substrates by chromate ion in polar medium, such studies on the monochromate oxidation of benzyl alcohols under PTC are scanty and hence the present work is reported.

The present work has been carried out to study the kinetics of selective oxidation of benzyl alcohol and substituted benzyl alcohols by chromate ion under PTC in organic medium. The substitutents used are $\mathrm{p}-\mathrm{OCH}_{3}, \mathrm{p}-\mathrm{CH}_{3}$ and p-Cl benzyl alcohols. Tetrabutylphosphonium bromide (TBPB) and tetrabutylammonium bromide (TBAB) are used as PT catalysts. The effect of substituents on the rate of oxidation of benzyl alcohol was studied and the results were correlated by plotting Hammett plot. A suitable mechanism is proposed based on the observations obtained. The novelty of the work is that the oxidation of benzyl alcohol and substituted benzyl alcohols by chromate ion in organic medium under PTC condition is very rapid, smooth, efficient, simple and highly selective with high yield and so kinetics of such reaction can be easily followed.

\section{Materials and Methods}

\subsection{Materials}

Analar grade potassium dichromate was used as the oxidant. Benzyl alcohol (AR) was further purified by vacuum distillation. The substituents $\mathrm{p}-\mathrm{OCH}_{3}, \mathrm{p}-\mathrm{CH}_{3}$ and $\mathrm{p}$ - $\mathrm{Cl}$ benzyl alcohols (Lancaster, England) and the PT catalysts, TBPB and TBAB (Merck KGaA, Germany) were used as such. Benzene was purified by reported methods [8] and doubly distilled water was used throughout this study.

\subsection{General procedure}

The extraction of monochromate into benzene was successfully carried out under the condition where $\mathrm{Bu}_{4} \mathrm{~N}^{+}: \mathrm{C}_{2} \mathrm{O}_{7}{ }^{2-}$ was $2: 1$ in presence of $2 \mathrm{M}$ sulphuric acid. Starks and Liotta [9] had given an account of chromate extraction, particularly, $\mathrm{HCrO}_{4}, \mathrm{CrO}_{4}^{2-}, \mathrm{HCr}_{2} \mathrm{O}_{7}$ and $\mathrm{Cr}_{2} \mathrm{O}_{7}{ }^{2-}$ into organic solvents using PT catalysts. It has been found that $\mathrm{HCrO}_{4}$ and $\mathrm{HCr}_{2} \mathrm{O}_{7}$ - are readily phase transferred when the aqueous phase is acidic. However, extraction of chromate does not take place when the aqueous phase is not acidic. The other two ions, $\mathrm{CrO}_{4}{ }^{2-}$ and $\mathrm{Cr}_{2} \mathrm{O}_{7}{ }^{2-}$ which are difficult to be transferred into the organic medium due to the difficulty in transferring a bivalent ion.

The kinetic measurements were carried out under conditions $\left[\mathrm{PhCH}_{2} \mathrm{OH}\right] \gg\left[\mathrm{Q}^{+} \mathrm{HCrO}_{4}\right]$ where $\mathrm{Q}^{+}$is quaternary onium cation. Schimadzu 1601 UV-Visible double beam spectrophotometer (Japan) was used to follow the reaction and was monitored by measuring the absorbance of $\mathrm{HCrO}_{4}$ - ions at $365 \mathrm{~nm}$. The experiments were repeated and the pseudo-first order rate constants, $k_{\text {obs }}$ were computed from the linear least square plots of $\log \left[\mathrm{HCrO}_{4}\right]$ versus time.

Potassium dichromate $\left(0.05 \mathrm{~mol} \mathrm{dm}^{-3}\right)$ solution containing $2.0 \mathrm{~mol} \mathrm{dm}^{-3} \mathrm{H}_{2} \mathrm{SO}_{4}$ was equilibrated with purified benzene containing PT catalysts either TBAB or TBPB $\left(0.1 \mathrm{~mol} \mathrm{dm}^{-3}\right)$. The monochromate ions are phase transferred to organic medium and the organic layer containing the oxidant was separated and dried over anhydrous sodium sulphate. The oxidant concentration was estimated by spectrophotometric method and is found to be stable for more than ten hours enabling convenient kinetic study. A known volume of $\mathrm{Q}^{+} \mathrm{HCrO}_{4^{-}}$was mixed with known volume of benzene and the mixture was thermostated for 30 minutes at the desired temperature. Required volume of previously thermostated alcohol in benzene was added to the above solution using a calibrated pipette. The progress of reaction is followed by withdrawing aliquots of reaction mixture at definite time intervals and the concentration of $\mathrm{Q}^{+} \mathrm{HCrO}_{4}^{-}$is measured spectrophotometrically.

\section{Results and Discussion}

The product of the reaction, corresponding benzaldehydes were identified as its 2,4dinitrophenylhydrazone (DNP) and the yield of the products was above $90 \%$. The stoichiometry of the reaction was found to be as one mole of the oxidant is equivalent to three moles of alcohols.

$$
3 \mathrm{PhCH}_{2} \mathrm{OH}+\mathrm{Cr}(\mathrm{VI}) \rightarrow \underset{6 \mathrm{H}^{+}}{3} \underset{\mathrm{PhCHO}}{6 \mathrm{Cr}(\mathrm{IV})}+
$$

It has been already reported that the reaction is first order each in [chromate ions] and [alcohol] and the rate of reaction was found to increase with the increase in dielectric constant of the medium upon changing the solvents [3]. This has proved that the reaction may be due to the interaction between a negative ion $\left(\mathrm{HCrO}_{4}{ }^{-}\right)$and a dipole (alcohol).

The reaction proceeds smoothly without any 
complex events and it is proved by the sequential scanning absorption spectra of the reaction system (Figure 1). The sequential scan of the absorption spectra for the oxidation of benzyl alcohol using $\mathrm{Q}^{+} \mathrm{HCrO}_{4} \cdot\left(\mathrm{Q}=\mathrm{TBP}^{+}\right)$in benzene at regular intervals of time showed isosbectic points at $321 \mathrm{~nm}$ and $394 \mathrm{~nm}$.

The effect of substituents on the rate of oxidation of benzyl alcohol has been investigated and is given in Table 1 . The rate constants obtained were found to be in the order of $\mathrm{p}-\mathrm{OCH}_{3}$ $>\mathrm{p}-\mathrm{CH}_{3}>\mathrm{H}>\mathrm{p}$-Cl. The electron-releasing substituents accelerate the oxidation process while the electron-withdrawing substituents retard the process. The plots of log $\mathrm{k}_{2}$ of benzyl alcohols versus substituent constant (s) gives a smooth curve (Figure 2). Such curve is obtained at all temperatures studied and is similar in all cases. This is evident even when log $\mathrm{k}_{2}$ is correlated with either $\sigma^{+}$or $\sigma$-instead of $\sigma$. So it has been assessed that the deviation from linearity in Hammett's plot is not due to change in $\sigma$. The curved shape of Hammett's plot may be due to the gradual change in the mechanism on

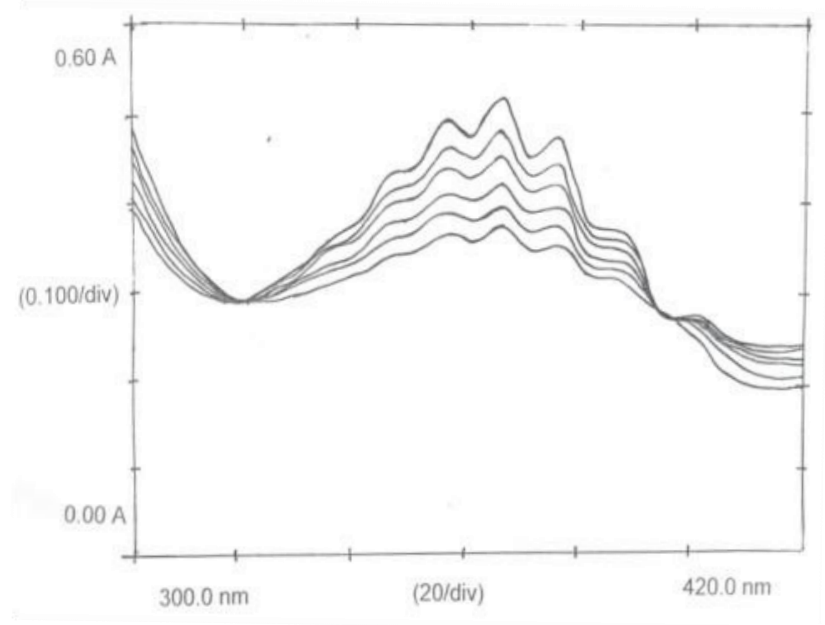

Figure 1. Absorption spectrum of the successive scans for the oxidation of benzyl alcohol by $\mathrm{Q}^{+} \mathrm{HCrO}_{4}^{-}\left(\mathrm{Q}=\mathrm{TBP}^{+}\right)$in benzene at $308 \mathrm{~K}$ (isosbestic points at $321 \mathrm{~nm}$ and $394 \mathrm{~nm}$ ) passing from electron donating to electron withdrawing substituents or a change in the rate determining step with change in nature of the substituent or change in the nature of the transition state. The polar reaction constants ( $\rho$ ) obtained were -0.4463 and -0.4396 for TBPB and TBAB respectively. The effect of temperature on the rate of oxidation of benzyl alcohols was carried out in the range $303 \mathrm{~K}$ to $318 \mathrm{~K}$ and is presented in Table 2.

The values of various activation parameters were determined and are presented in Table 3. The activation enthalpies and entropies for the oxidation of benzyl alcohols are linearly related $(\mathrm{r}=09981$ and 0.9988 for TBPB and TBAB respectively). The correlation between $\Delta \mathrm{H}^{\#}$ and $\Delta \mathrm{S}^{\#}$ was tested and found valid by applying Exner's [10-11] criterion by plotting log $\mathrm{k}_{2}$ at 313 $\mathrm{K}$ and $\log \mathrm{k}_{2}$ at $303 \mathrm{~K}(\mathrm{r}=0.9941$ and 0.9946 for TBPB and TBAB, respectively). The isokinetic temperature obtained from $\Delta \mathrm{H}^{\#}$ vs $\Delta \mathrm{S}^{\#}$ plot is 381 and $385 \mathrm{~K}$ for TBPB and TBAB respectively and from Exner's plot the isokinetic temperature obtained is 387 and $357 \mathrm{~K}$ for TBPB

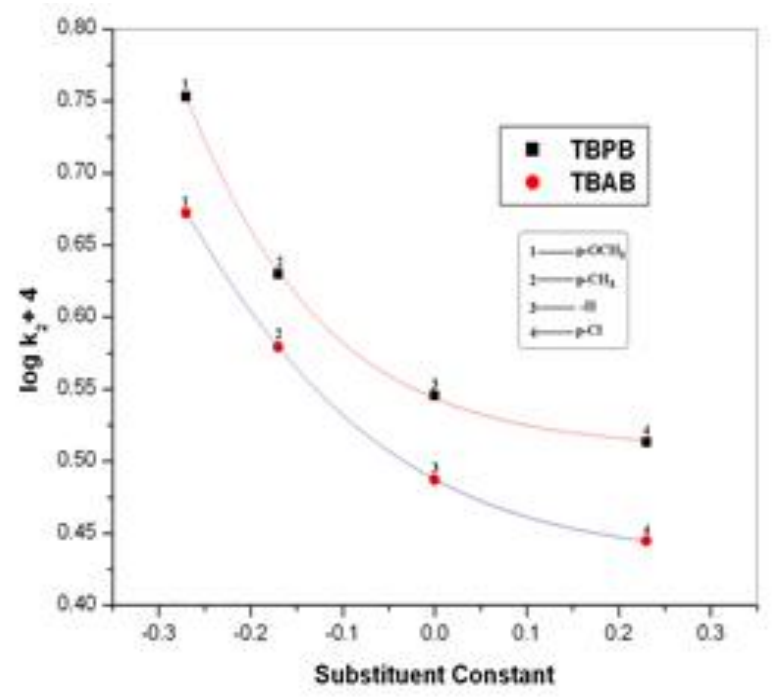

Figure 2. Hammett Plot for the oxidation of benzyl alcohols

Table 1. Effect of substituents on the rate of oxidation of benzyl alcohol $\left(\left[\mathrm{Q}^{+} \mathrm{HCrO}_{4}\right]\right.$ x $10^{3}=5.0 \mathrm{~mol}$ $\mathrm{dm}^{-3}$; Medium: Benzene; [Substrate] x $10^{1}=2.0 \mathrm{~mol} \mathrm{dm}^{-3}$; Temperature: $303 \mathrm{~K}$ )

\begin{tabular}{ccc}
\hline Substrate & $\mathrm{k}_{2} \times 10^{4}\left(\mathrm{dm}^{3} \mathrm{~mol}^{-1} \mathrm{~s}^{-1}\right)$ & $\mathrm{k}_{2} \times 10^{4}$ \\
$(\mathrm{BA}-\mathrm{Benzyl}$ alcohol $)$ & PT Catalyst - TBPB & PT Catalyst $-\mathrm{TBAB}$ \\
\hline $\mathrm{PhCH}_{2} \mathrm{OCH}$ & 3.5121 & 3.0707 \\
$\mathrm{p}-\mathrm{OCH}_{3} \mathrm{BA}$ & 5.6654 & 4.7036 \\
$\mathrm{p}-\mathrm{CH}_{3} \mathrm{BA}$ & 4.2649 & 3.7945 \\
$\mathrm{p}-\mathrm{Cl} \mathrm{BA}$ & 3.2620 & 2.7828 \\
\hline
\end{tabular}


and TBAB respectively. These results suggest that similar mechanism operates for the oxidation of all alcohols. This is further confirmed from the almost constant value of the free energy of activation $\left(\Delta \mathrm{G}^{\#} \approx 94 \mathrm{~kJ} \mathrm{~mol}^{-1}\right)$.

PT catalysts help in transferring the reactive anion, $\mathrm{HCrO}_{4}$ - from the aqueous acidic medium into the organic medium as an ion-pair $\left.\left(\mathrm{Q}^{+} \mathrm{HCrO}_{4}\right)^{-}\right)$. The reaction proceeds through the interaction of the oxidant with the substrate alcohol to form a complex in the organic medium which subsequently disproportionate to the product. The formation of chromate ester as an intermediate in a pre-equilibrium step has been already reported [6-7]. The chromate ester is formed by the interaction of ${ }^{2} \mathrm{P}$ - electrons on the HOMO of oxygen in alcohol with LUMO of the chromium [12]. The rate determining step involves the decomposition of the chromate es- ter via cyclic Huckel type transition state and it comprises the cleavage of a C-H bond and $\mathrm{O}-\mathrm{Cr}$ bond forming the product [13-14]. The negative value of the polar reaction constant together with substantial deuterium isotope effect indicates that the transition state approaches a carbocation in character. Hence the transfer of hydride ion from the alcohol to the oxidant is suggested. The hydride ion transfer may take place either by a cyclic process via an ester intermediate or by an acyclic one step bimolecular process. The chromate ester has greater stability in organic solvents than in water and is reported elsewhere [15-16]. The negative $\Delta \mathbf{S}^{\#}$ values support the formation of the chromate ester with high degree of orderedness with cyclic intermediate formation. The occurrence of concerted one step bimolecular process by hydrogen transfer is ruled out by Bordwell [17]. It

Table 2. Effect of temperature on the rate of oxidation of benzyl alcohols $\left(\left[\mathrm{Q}^{+} \mathrm{HCrO}_{4}\right] \mathrm{x} 10^{3}=5.0\right.$ mol dm ${ }^{-3}$; Medium: benzene; [Substrate] x10 $10^{1}=2.0 \mathrm{~mol} \mathrm{dm}^{-3}$ )

\begin{tabular}{|c|c|c|c|c|}
\hline \multirow{2}{*}{$\frac{\text { Substrate }}{\text { (BA - Benzyl alcohol) }}$} & \multicolumn{4}{|c|}{$\mathrm{k}_{2} \times 10^{4}\left(\mathrm{dm}^{3} \mathrm{~mol}^{-1} \mathrm{~s}^{-1}\right)$ at temp $(\mathrm{K})$} \\
\hline & 303 & 308 & 313 & 318 \\
\hline \multicolumn{5}{|l|}{$\mathrm{PhCH}_{2} \mathrm{OH}$} \\
\hline TBPB & 3.5121 & 4.2989 & 4.9707 & 6.1414 \\
\hline TBAB & 3.0707 & 3.8959 & 4.6444 & 5.4312 \\
\hline \multicolumn{5}{|l|}{$\mathrm{p}-\mathrm{OCH}_{3} \mathrm{BA}$} \\
\hline TBPB & 5.6654 & 6.3963 & 7.6959 & 8.9044 \\
\hline TBAB & 4.7036 & 5.5744 & 6.4517 & 7.7321 \\
\hline \multicolumn{5}{|l|}{$\mathrm{p}-\mathrm{CH}_{3} \mathrm{BA}$} \\
\hline ТВРВ & 4.2649 & 5.2635 & 5.8381 & 7.3318 \\
\hline TBAB & 3.7945 & 4.6499 & 5.6879 & 6.3815 \\
\hline \multicolumn{5}{|l|}{$\mathrm{p}-\mathrm{Cl} \mathrm{BA}$} \\
\hline TВPB & 3.2620 & 3.9628 & 4.8708 & 5.8765 \\
\hline TBAB & 2.7828 & 3.5071 & 4.3115 & 5.1050 \\
\hline
\end{tabular}

Table 3. Activation parameters for the oxidation of benzyl alcohol (Medium: Benzene; Temperature: $303 \mathrm{~K}$ )

\begin{tabular}{ccccc}
\hline Substrate & $\begin{array}{c}\mathrm{Ea} \\
\left(\mathrm{kJ} \mathrm{mol}^{-1}\right)\end{array}$ & $\begin{array}{c}\Delta \mathrm{H}^{\#} \\
\left(\mathrm{~kJ} \mathrm{~mol}^{-1}\right)\end{array}$ & $\begin{array}{c}-\Delta \mathrm{S}^{\#} \\
\left(\mathrm{~J} \mathrm{~K} \mathrm{~mol}^{-1}\right)\end{array}$ & $\begin{array}{c}\Delta \mathrm{G}^{\#} \\
\left(\mathrm{~kJ} \mathrm{~mol}^{-1}\right)\end{array}$ \\
\hline $\mathrm{PhCH}{ }_{2} \mathrm{OH}$ & & & & \\
$\mathrm{TBPB}$ & 29.19 & 26.61 & 223.40 & 94.30 \\
$\mathrm{TBAB}$ & 30.28 & 27.70 & 220.92 & 94.64 \\
$\mathrm{p}-\mathrm{OCH}{ }_{3} \mathrm{BA}$ & & & & \\
$\mathrm{TBPB}$ & 24.70 & 22.11 & 234.28 & 93.10 \\
$\mathrm{TBAB}$ & 26.24 & 23.65 & 230.74 & 93.57 \\
$\mathrm{p}-\mathrm{CH}_{3} \mathrm{BA}$ & & & & \\
$\mathrm{TBPB}$ & 27.70 & 25.12 & 226.71 & 93.81 \\
$\mathrm{TBAB}$ & 28.27 & 25.69 & 225.80 & 94.11 \\
$\mathrm{p}-\mathrm{Cl} \mathrm{BA}$ & & & & \\
$\mathrm{TBPB}$ & 31.61 & 29.07 & 215.90 & 94.49 \\
$\mathrm{TBAB}$ & 32.51 & 29.94 & 214.35 & 94.89 \\
\hline
\end{tabular}


has been already proved that intrinsically concerted sigmatropic reactions, characterized by transfer of hydrogen in a cyclic transition state are the only truly symmetrical processes involving a linear hydrogen transfer [12]. Littler [18] has proved that a cyclic hydride transfer in the oxidation of alcohols by $\mathrm{Cr}(\mathrm{VI})$, involves six electrons and being a Huckel type system, is an allowed process. Thus the decomposition of ester intermediate takes place through a planar, cyclic and symmetrical transition state. Thus the overall mechanism proposed is to involve the formation of a chromate ester in a fast preequilibrium step and then the disproportionation of the ester in a subsequent slow step via a cyclic concerted symmetrical transition state leading to the product. The mechanism can be formulated as:

$\left[\mathrm{Q}^{+} \mathrm{HCrO}_{4}^{-}\right]_{\mathrm{H}_{2} \mathrm{O}} \rightleftharpoons\left[\mathrm{Q}^{+} \mathrm{HCrO}_{4}^{-}\right]_{\text {org }}$

The phase transferred $\mathrm{Q}^{+} \mathrm{HCrO}_{4}$ - reacts with alcohol in the organic medium as follows:

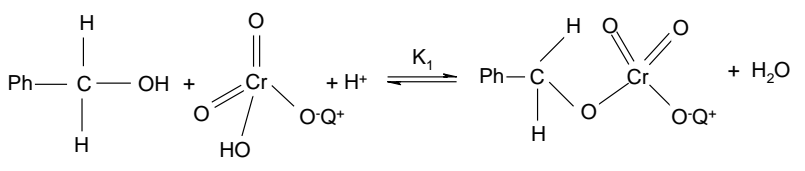

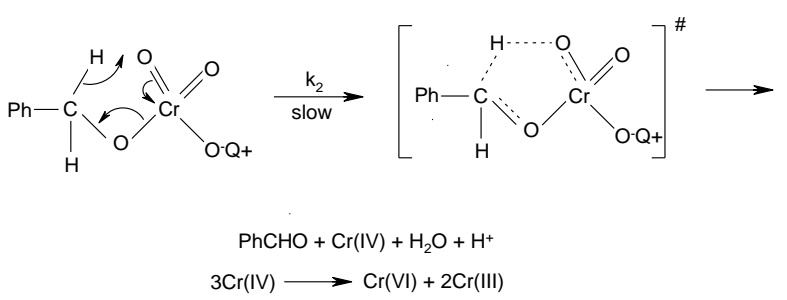

$\mathrm{Cr}$ (IV) formed in the reaction is unstable in the organic medium and undergoes fast disproportionation to $\mathrm{Cr}$ (III).

A suitable rate expression for the oxidation of benzyl alcohols using phase transferred monochromate in consistent with the above mechanism can be proposed as:

$$
\begin{aligned}
\frac{-\mathrm{d}\left[\mathrm{HCrO}_{4}^{-}\right]}{\mathrm{dt}}=\mathrm{k}_{2} & \text { [complex }] \\
& =\mathrm{K}_{1} \mathrm{k}_{2}\left[\mathrm{PhCH}_{2} \mathrm{OH}\right]\left[\mathrm{HCrO}_{4}{ }^{-}\right]
\end{aligned}
$$

\section{Conclusions}

The selective oxidation of benzyl alcohols by acidified monochromate under phase transfer catalysis gave corresponding aldehydes as product. The reaction was highly selective and the yield was above 90\%. Electron donating substituents enhanced the reaction rate while electron withdrawing substituents retarded the rate. Hammett's linear free energy relationship was not obeyed and a smooth curve is obtained. The reaction sequence involved the formation of chromate ester which on decomposition in a slow rate determining step gives the product. This reaction did not occur in organic medium without the presence of PT catalysts and thus by using PT catalysts, it is easy to follow the kinetics of such type of reactions and mechanism can be arrived.

\section{References}

[1] Wiberg, K. B. (1965). Oxidation in Organic Chemistry. Academic Press, London and New York.

[2] Lee, D. G. (1980). Oxidation of Organic Compounds by Permanganate ion and Hexavalent Chromium, Open Court: La Salle.

[3] Bijudas, K., Radhakrishnan Nair, T.D. (2004). Selective oxidation of benzyl alcohol with monochromate in non - polar solvents. Indian Journal of Chemistry. 43A: 1216-1218.

[4] Basheer, M.K., Joseph, J., Nair, T.D.R. (2007). Catalysis by onium salts on the monochromate oxidation of benzhydrols in non polar media - A kinetic study. Indian Journal of Chemistry. 46A: $273-275$.

[5] Bijudas, K., Radhakrishnan Nair, T.D. (2014). Kinetics and mechanism of the selective oxidation of primary aliphatic alcohols under phase transfer catalysis. Current Chemistry Letters. 3(2): 109-114. (DOI: 10.5267/j.ccl.2013.12.001).

[6] Pletcher, D., Tait, S.J.D. (1979). A procedure for the oxidation of alcohols to aldehydes based on phase transfer catalysis. Journal of the Chemical Society, Perkin Transactions 2. 6: 788-791.

[7] Pletcher, D., Tait, S.J.D. (1978). The oxidation of alcohols and aromatic hydrocarbons by dichromate in two phase systems. Tetrahedron Letters. 18: 1601-1602.

[8] Perrin, D.D., Armarego, W.L., Perrin, D.R. (1966). Purification of organic compounds, Oxford: Pergamon Press.

[9] Starks, C.M., Liotta, C.L. (1978). Phase Transfer Catalysis, Principles and Techniques, Academic Press: New York.

[10] Exner, O. (1964). On the enthalpy- entropy relationship. Collection of Czechoslovak Chemical Communications. 29: 1094 -1113.

[11] Exner, O. (1964). Concerning the isokinetic relationship. Nature, 201: 488-490. (DOI: 10.1038/201488b0) 
[12] Woodword, R.B., Hoffmann, H. (1969). The conservation of orbital symmetry. Angewandte Chemie International Edition in English. 8: 781-932.

[13] Banerji, K.K. (2013). Structure-reactivity correlation in the oxidation of substituted benzyl alcohols by imidazolium flourochromate. European Chemical Bulletin. 2(10): 816-824.

[14] Banerji, K.K. (1988). Oxidation of substituted benzyl alcohols by pyridinium fluorochromate: a kinetic study. Journal of Organic Chemistry. 53: 2154-2159.

[15] Beattie, J.K., Haight, G.P.Jr. (1972). Chromium (IV) oxidation of inorganic substrates. Progress in Inorganic Chemistry: Inorganic reaction mechanism: Part II, 17: 93-145.
[16] Wiberg, K.B., Schafer, H. (1969). Chromic acid oxidation of isopropyl alcohol. Preoxidation equilibria. Journal of American Chemical Soceity. 91: 927- 932.

[17] Bordwell, F.G. (1974). How common are baseinitiated, concerted 1,2 eliminations. Accounts of Chemical Research. 5: $374-384$.

[18] Littler, J.S. (1971). Oxidation of olefins, alcohols, glycerols and other organic compounds, by inorganic oxidants such as chromium(VI), manganese(VII), iodine(VII), lead(IV), vana$\operatorname{dium}(\mathrm{V})$ and halogens, considered in the light of the selection rules for electrocyclic reactions. Tetrahedron. 27: 81-91. 